\title{
Arguments for zero tolerance of sexual contact between doctors and patients
}

\author{
R M Cullen Avondale Family Health Centre, Avondale, Auckland, New Zealand
}

\begin{abstract}
Some doctors do enter into sexual relationships with patients. These relationships can be damaging to the patient involved. One response available to both individual doctors and to disciplinary bodies is to prohibit sexual contact between doctors and patients ("zero tolerance").

This paper considers five ways of arguing for a zero tolerance policy. The first rests on an empirical claim that such contact is almost always harmful to the patient involved. The second is based on a "principles" approach while the third originates in "virtues" ethics. The fourth argues that zero tolerance is an "a priori" truth. These four attempt to establish that the behaviour is always wrong and ought, therefore, to be prohibited.

The fifth argument is counterfactual. It claims a policy that allowed sexual contact would have unacceptable consequences. Given the responsibility of regulatory bodies to protect the public, zero tolerance is a natural policy to develop.
\end{abstract}

(Fournal of Medical Ethics 1999;25:482-486)

Keywords: Sexual contact; zero tolerance

\section{Introduction}

Is it morally acceptable for doctors to have sex with their patients? A simple answer is "no". Such an answer has the benefit, if enforced, of possibly preventing some harms from befalling some patients. This paper attempts to outline five arguments that can be used to defend such a "zero tolerance" answer.

The first argument is empirical. It is commonly based on the premise that sexual contact between doctors and patients is almost always harmful to patients. Despite the frequency with which this premise is stated as fact it simply is not true in so far as the facts are presently known. A modified version of the empirical argument treats sexual contact as though it were a medical intervention like surgery or drugs.

The second argument is that there is a tension between a decision to have sex with a patient and the principles that govern medical decision making. However, this relies critically on the facts of each particular case and the most general con- clusion that can be drawn is that such sexual relst tions are "ill advised" and "hazardous".

The third argument is Aristotelian in origin. $\overrightarrow{\vec{\phi}}$ considers the virtues necessary in a good medicent practitioner and attempts to demonstrate that virtuous doctor cannot enter a sexual relationsh with a patient. ${ }^{2}$

The fourth argument is an "a priori" one. rests on the definitions of "doctor" "patient" and "sexual partner". If these definitions are accepted, then zero tolerance is a logical necessity which arises out of the meaning of the words.

The fifth argument is counterfactual. It asser that the consequences of a policy that allowege sexual contact between doctors and patients would be harmful.

\section{Almost always harmful?}

An influential editorial in the British Medical fou nal asserted that sexual contact between doctogs and patients was almost always harmful to the patient. $^{3}$

When this premise is accepted as fact and used to draw the conclusion that sexual contact shou住 never take place between doctors and patients, the argument takes the following form (using well-known example):

P1. Thalidomide is almost always harmful

P2. Almost always harmful drugs ought never be used.

Conclusion. Thalidomide ought never to be used.

The doctor who wishes to have sex with a patie can get around this argument while accepting the truth of both premisses. He makes an exceptiof for himself by arguing that while there are lots $\mathrm{af}$ cases where sexual contact is clearly wrong-this unwelcome abusive advances perhaps even pef formed under cover of anaesthesia by miscreants who should be struck from the register forthwitfl, what he and Miss Jones share is something quite different. They are consenting adults who feed deeply for each other, the victims of Cupidos arrows. $\mathrm{He}$ is just a coach in their profession relationship. Both he and Miss Jones are quite abse to separate their professional and personal roles 
One thing this objection uncovers is a hidden premise in the argument. A fuller version is:

P1. Thalidomide is almost always harmful.

HP. It is impossible to predict who will not be harmed by thalidomide

P2. Almost always harmful drugs where it is impossible to predict who will not be harmed ought never to be used.

Conclusion. Thalidomide ought never to be used.

The doctor who wishes to make an exception for himself has claimed to be able to identify Miss Jones as someone who will not be harmed by sexual contact with him. Medicine has a history of charlatans who claim to be able to distinguish the "special cases" who will benefit from interventions that are, in general, dangerous. They claim skills not shared by their peers, and from which they make a personal gain. It is difficult to see how the doctor who wishes to make an exception for himself escapes the charge that he is behaving like such a quack.

\section{Representative sample}

However, any doctor who wishes to have sex with a patient can deny the truth of the first premise. What would it take to prove that sexual contact between doctors and patients is almost always harmful to the patient?

Some sort of survey would be needed. It would need to be valid, ie the survey instrument would have to determine accurately whether a respondent had been harmed by the sexual contact. The sample size would need to be such that the confidence interval for the proportion of patients harmed did not include any number smaller than "almost always". The sample would need to be representative of patients who have had sexual contact with doctors. No such survey has ever been performed.

The evidence in support of the "almost always harmful" claim is not strong. It consists largely of case reports and (small) series of patients who are seeing psychotherapists. The subjects involved are highly selected rather than representative.

On the other hand, many health professionals can identify colleagues who have married patients. A large survey of New Zealand physiotherapists revealed that $1 \%$ had married a patient. ${ }^{4}$ Sexual contact in the professional relationship is common. Five per cent of New Zealand general practitioners (self) report sexual contact with a current patient. ${ }^{5}$ The corresponding figures for New Zealand physiotherapists are $11 \%$ of males and $7 \%$ of females. ${ }^{6}$

In contrast, complaints to disciplinary bodies alleging sexual misconduct by a health profes- sional are rare even though the behaviour is common. Correspondence in the New Zealand Family Physician revealed that in the three years from mid-1991 to mid-1994 only thirty such complaints were received by the Medical Council of New Zealand. ${ }^{78}$ Sixteen of these did not even get as far as a formal hearing because "there was no case to answer".

The survey of New Zealand general practitioners uncovered too few (11) general practitioners who had had sexual contact with either a current or former patient to enable any conclusions to be drawn about how general practitioners view the effect of that contact on their patients. ${ }^{5}$ However, 102 physiotherapists reported sexual contact with either a current or former patient. Of these, only five thought the contact had had a negative effect on the patient, while 64 thought the effect had been positive. That is, the involved physiotherapist is twelve times more likely to report that the contact had a positive effect on the patient.

Doctors have tolerant views towards sexual contact with patients as do physiotherapists. ${ }^{49}$ This suggests that their intuitions are not in accord with the premise that sexual contact is almost always harmful to the patient.

In summary, the claim that sexual contact between doctors and patients is almost always harmful to the patient is not supported by evidence of the required type. Available evidence: that sexual contact is common while complaints about it are not; that it is most often perceived by the professional involved as having a positive effect, and that both doctors and physiotherapists believe a variety of scenarios to be acceptable, combine to suggest that sexual contact is only sometimes harmful to the patient (although that harm is often severe).

But this may be all that is needed. The argument can be modified to read:

P1. Sexual contact between a doctor and a patient is sometimes devastatingly harmful to the patient.

P2. There are never any patients whose lives are saved by sexual contact with their doctor.

P3. It is impossible to predict which patients will not be devastatingly harmed by sexual contact with their doctor

P4. Interventions which are sometimes devastatingly harmful, which are never life-saving and where it is impossible to predict who will not be harmed ought never to be undertaken.

Conclusion. Sexual contact between a doctor and a patient ought never to be undertaken.

This is a strong argument. It treats sexual contact as just another thing that doctors do to patients. 
The challenge to any doctor contemplating, or engaged in, sexual contact with a patient is to make a legitimate exception for him (or, less commonly, her) self.

\section{Principles}

An alternative way of approaching the ethical question is to list the relevant underlying ethical principles and consider whether the proposed course of action is consistent with each of them. This principles-based approach to medical ethics is expounded in Gillon's standard text. ${ }^{10}$

Doctors may be familiar with principles such as autonomy and beneficence. Zelas has proposed a set of necessary conditions which must be met if sexual contact is to be acceptable. ${ }^{1}$ They are trust, power balance, and consent. If there is any breach of trust then the behaviour is wrong. If there is a power imbalance then sexual contact is not ethical. If there is not valid consent then sexual contact is not permissible.

The very influential final report of the Task Force on Sexual Abuse of Patients commissioned by the College of Physicians of Ontario ${ }^{11}$ abuses this kind of reasoning in making statements like "due to the position of power the physician brings to the doctor-patient relationship, there are NO circumstances - NONE - in which sexual activity between a physician and a patient is acceptable" and "due to the power the physician brings to the physician-patient relationship, there is no such thing as gaining consent for sexual involvement with a patient".

These comments are an abuse of principlesbased arguments because the probability of a power imbalance or of invalid consent does not imply their certainty.

Even if one accepts trust, power balance, and consent as necessary conditions they do not lead to a zero tolerance position as it is possible to imagine sets of circumstances where all three are complied with. Moreover, it seems as if the list of principles could be continued indefinitely and there would still be circumstances where all were complied with. One cannot leap from a realisation that in some circumstances telling the truth (or sexual contact) can be "ill advised" and "hazardous" (to use Zelas's conclusions about sexual contact between doctors and patients) to a conclusion that it is always, or even generally, wrong to tell the truth.

\section{Virtues-based argument}

What are the traits of character which need to be developed and practised in a doctor so that he (or she) performs his (or her) function well? Are these compatible with sexual contact between a doct $\frac{\Phi^{2}}{c}$ and a patient? Or is it the case that what it takes tho be a good doctor precludes sexual contact witi any patient?

A virtues ethicist might claim that a good do tor has (permanent and fixed) dispositions to aff in certain ways and that those dispositions af

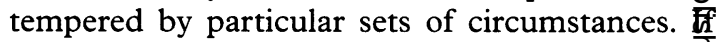
this is so then an important purpose of clinic裹 education is to develop the appropriate disposio tions (virtues) and to expose the student to praes ceptors who have both the dispositions and the practical wisdom to exercise them appropriately. $\vec{\omega}$

McCullough, Chervenak and Coverdale have attempted to demonstrate that zero tolerance is necessary consequence of an appropriate idea the virtues necessary for creating and sustaining the doctor-patient relationship. ${ }^{2}$ They assert thas doctors are necessarily self-effacing and sele sacrificing. The self-effacement obligates the phy sician to set aside any sexual feelings a patient may arouse in him. The self-sacrifice obligates him th forgo the pursuit of sexual satisfaction.

The weakness of this line is that it twists the concept of virtue until virtues become duties to be followed regardless of circumstances. But now they are no longer virtues. Moreover, it seense possible to imagine circumstances in which a le effacing and self-sacrificing doctor could falsi love with, and be loved by, a patient.

\section{A priori argument}

Is there something about a doctor-patient rel产 tionship that is inconsistent with a sexual relation ship? This is not a question of fact, but of mear ing. If the affirmative answer is set out as an argument it might look like this

Premise. The doctor-patient relationship mus have "property X" (by definition)

Premise. The relationship between sexual con tacts cannot have "property X" (bg

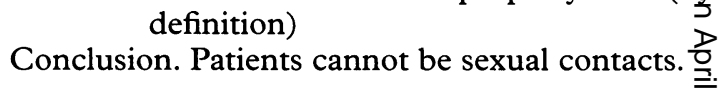

Many doctors seem to have an intuitive idea tha such a property, or such properties, do exist. Fromo this arises the idea that doctors ought not to treab their spouses. Indeed, there are a number of per:sonal relationships which may be substituted for "sexual contacts". Examples are "children", and "close friends".

A candidate "property $X$ " is the notion of professional boundary (emotional distance, de्⿱一𫝀) tachment). Another candidate is the doctor's abif ity to set aside both his and the patient's emotion states for the duration of the consultation whict 
may occur at any time of the day or night and involve any problem at all.

Of course, it is open to any practitioner to deny the existence of any such "property X". Or if the existence of such a property is conceded he can claim that it can survive this particular sexual relationship

\section{Counterfactual argument}

This paper opened with the question: "Is it morally acceptable for doctors to have sex with their patients"? The argument in this section does not address the question directly. It first attempts to establish that, as a matter of policy, sexual contact between doctors and patients ought to be prohibited. Then, its proponents proceed with an assertion that doctors have a moral obligation to comply with such a prohibition. If this is true then it follows, as a matter of definition, that doctors who have sexual contact with patients have behaved immorally.

The question about what the appropriate policy ought to be is, perhaps, more urgent in many parts of the world than that about the morality of sexual contact between doctors and patients in the absence of any policy. The counterfactual argument offers a direct route to prohibition without the difficult task of first showing that the act is necessarily immoral.

The counterfactual argument may be summarised as:

P1. If sexual contact between doctors and patients were allowed then there would be unacceptable consequences.

Conclusion. Sexual contact between doctors and patients should not be allowed.

This is both a common and influential argument form in bioethics. It has been used to oppose in vitro fertilisation, legalisation of abortion, euthanasia, and more recently, human cloning. Its influence is not reduced by the failure of postulated uncertain negative future consequences to have arisen on some previous occasions. In the same way, even if the last ten tosses of an unbiased coin have resulted in heads, the next might be a tail. However, the counterfactual argument must be treated with caution for it does not require strong empirical evidence, may rest on vague concerns and prejudices, and cannot specify the probability of the unacceptable consequences predicted.

A typical "unacceptable consequence" relied on is a postulated breakdown of the trust essential to a doctor-patient relationship. I take it as selfevident that if the consulting room were perceived by some patients as a place where unwelcome sexual advances might occur, or if some doctors did view patients as objects for their sexual gratification, then patients would be justified in trusting their doctors less.

Other candidate "unacceptable consequences" have been discussed in earlier sections. For example, it can be argued that if sexual contact between doctors and patients is allowed, then neither the professional boundaries nor the emotional detachment necessary for the practice of good medicine can be maintained.

The claim that doctors have a moral obligation to comply with a prohibition on sexual contact with patients when such a prohibition exists can also be supported by an appeal to "trust in the professional relationship". A pillar of such trust is that doctors have a code of professional behaviour that they all adhere to at all times. No doctor can excuse himself from the profession's moral code. Therefore, doctors can be trusted to behave in accordance with the code. They respect confidentiality for example, because it is part of the code and because it is part of the code doctors can be trusted to respect confidentiality.

\section{Discussion}

This paper began by posing the question: "Is it morally acceptable for doctors to have sex with their patients?" The counterfactual argument provides a clear "No", even if by something of an indirect route. It claims that doctors are morally obligated to adhere to their code of conduct, and that "zero tolerance" of sexual contact between doctors and patients is the appropriate stance for regulatory bodies to take. This stance protects the public from real harms that are known to occur in at least a proportion of cases where sexual contact occurs between doctors and patients. Regulatory bodies can be expected to act so as to reduce harms to the public rather than to allow an increase in harms even if there might be some compensatory benefits.

The first four arguments (empirical, principles, virtues, a priori) demonstrated that, in the absence of any "zero tolerance" policy, there are possible cases where sex between doctors and patients is not morally blameworthy. However, the doctor involved is in an unenviable position to judge any of his own true motivations, the quality of the consent offered by the patient, the likelihood of harm accruing to the patient, or the effect of such a relationship on the doctor-patient relationship.

\section{Acknowledgements}

Earlier versions of this paper were presented to a Diploma of Professional Ethics class at Auckland 
University and to the fourth annual conference of the Australian Association for Professional and Applied Ethics. The author is grateful for the helpful comments made by both audiences and for the improvements suggested by the journal's reviewers.

$R M$ Cullen MSc, MBChB, BA, is a General Practitioner at the Avondale Family Health Centre, Avondale, Auckland, New Zealand.

\section{References}

1 Zelas K. Sex and the doctor-patient relationship. New Zealand Medical fournal 1997;110: 60-2.

2 McCullough LB, Chervenak FA, Coverdale JH. Ethically justified guidelines for defining sexual boundaries between obstetrician-gynecologists and their patients. American fournal of Obstetrics and Gynecology 1996;175:496-500.
3 Fahy T, Fisher N. Sexual contact between doctors and patient感 British Medical fournal 1992;304:1519-20.

4 Cullen RM, Davidson M, Guthrie B. Sexual contact in the professional relationship - the 1996 survey of NZSP membes. New Zealand fournal of Physiotherapy 1997;25,2:7-9.

5 Coverdale JH, Thomson AN, White GE. Social and sexurat contact between general practitioners and their patients in Ne Zealand: attitudes and prevalence. British foumal of Genew Practice 1995;45:245-7.

6 Cullen RM, Davidson M, Guthrie B. Physiotherapists w have had sex with patients-the 1996 NZSP survev. $N e w Z$ e land Fournal of Physiotherapy 1997;25,3:7-9

7 Cullen R. Ask women about zero tolerance policy [letter]. $\lambda$ i⿱宀 Zealand Family Physician 1996; 23,6:13.

8 Thompson $\mathrm{K}$. They were asked, says council [letter]. New $Z_{c}$ 究 land Family Phvsician 1996;23,6:13-14.

9 Cullen RM, Northwood BR. Medical discipline and sexuad activity between doctors and patients. New Zealand Medical fournal 1995;108:481-3.

10 Gillon R. Philosophical medical ethics. Chichester: John Wil w్ and Sons, 1985 .

11 Task Force on Sexual Abuse of Patients. Report of Task Force Sexual Abuse of Patients. Commissioned and published by t College of Physicians of Ontario, Nov 1991.

\section{News and notes}

\section{Journal's editors honoured}

The founding editor of the fournal of Medical Ethics, Professor Alastair Campbell, Professor of Ethics in Medicine at Bristol University and the current editor, Professor Raanan Gillon, Professor of Medical Ethics at Imperial College School of
Medicine, London University, have been awarded the Henry Knowles Beecher Award of the Hastings Center, for contributions to ethics and the life sciences.

They are the first recipients outside the USA. 